\title{
Nitric oxide: promoter or suppressor of programmed cell death?
}

\author{
Yiqin Wang ${ }^{1}$, Chen Chen ${ }^{1,2}$, Gary J. Loake ${ }^{3}$, Chengcai Chu ${ }^{1}(\bowtie)$ \\ ${ }^{1}$ National Key Laboratory of Plant Genomics and National Centre for Plant Gene Research, Institute of \\ Genetics and Developmental Biology, Chinese Academy of Sciences, Beijing 100101, China \\ 2 Beijing Forestry University, Beijing 100083, China \\ ${ }^{3}$ Institute of Molecular Plant Sciences, School of Biological Sciences, University of Edinburgh, King's \\ Buildings, Edinburgh EH9 3JR, United Kingdom
}

$\triangle$ Correspondence: ccchu@genetics.ac.cn

Received November 13, 2009; accepted December 1, 2009

\begin{abstract}
Nitric oxide (NO) is a short-lived gaseous free radical that predominantly functions as a messenger and effector molecule. It affects a variety of physiological processes, including programmed cell death (PCD) through cyclic guanosine monophosphate (cGMP)-dependent and independent pathways. In this field, dominant discoveries are the diverse apoptosis networks in mammalian cells, which involve signals primarily via death receptors (extrinsic pathway) or the mitochondria (intrinsic pathway) that recruit caspases as effector molecules. In plants, PCD shares some similarities with animal cells, but NO is involved in PCD induction via interacting with pathways of phytohormones. NO has both promoting and suppressing effects on cell death, depending on a variety of factors, such as cell type, cellular redox status, and the flux and dose of local NO. In this article, we focus on how NO regulates the apoptotic signal cascade through protein S-nitrosylation and review the recent progress on mechanisms of PCD in both mammalian and plant cells.
\end{abstract}

KEYWORDS nitric oxide, S-nitrosylation, programmed cell death

\section{PCD IN MAMMALIAN AND PLANT CELLS}

Programmed cell death (PCD), or apoptosis in mammalian cells, is a mechanism by which cells activate an intrinsic suicide program. It is a sophisticatedly regulated cellular process that is essential for organ development and homeostasis (Vaux and Korsmeyer, 1999). PCD is characterized by cell shrinkage, membrane blebbing, chromatin condensation, DNA fragmentation and selective cleavage of proteins by caspases, which are a family of least 14 mammalian aspartate-specific, cysteine-protease isoenzymes (Hengartner and Bryant, 2000; Meier et al., 2000; Ameisen, 2002). Caspases are the central molecular initiators and executors of apoptosis. They are grouped into 'initiator caspases' and 'effector caspases' by structure and function (Nicholson and Thornberry, 1997; Thornberry and Lazebnik, 1998; Shi, 2002; Nicholson and Thornberry, 2003). Activation of 'initiator caspases' such as caspase-8 and -9 initiates a 'caspase cascade' in which downstream 'effector caspases', such as caspase-3, -6 and -7 , are cleaved by upstream initiator caspases to form active heterodimers, which then proteolyze specific protein substrates (Zhou et al., 2005). Caspases also cleave specific aspartate residues in other regulatory proteins, such as B cell lymphoma/lewkmia-2 (Bcl-2), Bcl-2 associated $\mathrm{x}$ protein (Bax) and mitogen-activated protein kinase/extracellular signal-regulated kinase (MAPK/ERK) kinase kinase (MEKK). To date, two main apoptosis pathways have been identified in mammalian cells. One is mitochondria-induced cell death, in which cytochrome $c$ is released from mitochondria in the presence of ATP and promotes the assembly of the apoptosome complex, including apoptotic protease-activating factor-1 and procaspase- 9 . Subsequently, apoptosome-mediated caspase- 9 cleavage leads to the activation of effector caspases and results in 
cell death. The alternative pathway is mediated by cell surface death receptors, such as tumor necrosis factor receptor (TNFR)-1 or factor associated suicide (Fas), which promote caspase-8 cleavage through adaptor molecules, and lead to apoptosis (Dragovich et al., 1998).

PCD also has an important role in plant growth, development and environmental responses. This process occurs during both the vegetative and reproductive phases of plant development, abiotic stress and interactions with pathogens. In addition to the more obvious forms of PCD, e.g., leaf senescence or hypersensitive response (HR) formation during the plant defense response (Elbaz et al., 2002), alternative programs of PCD include death-terminal differentiation during lysigenous aerenchyma formation and aleurone degradation throughout germination (Jones, 2001). Recent work has highlighted similarities in several aspects of plant and animal PCD formation, such as the formation of apoptotic bodies during HR development. Other morphological similarities, e.g., cytoplasm shrinkage, nuclear condensation and membrane blebbing (Levine et al., 1996; Wang et al., 1996), indicates that the basic molecular machinery underlying this process is well conserved in all eukaryotic organisms (Danial and Korsmeyer, 2004). It appears that collapse of the vacuole may be the universal trigger of plant cell death; however, death during the HR does not result in removal of cell corpses but does release toxins directed against the pathogen. Subsequently, these corpses are crushed by the expanding tissues. Such a "messy" death might be part of the cell's strategy for defense (Jones, 2001). Cathepsins are a family of lysosomal noncaspase cysteine and aspartate proteases involved in mammalian apoptosis. Recent studies on a Cathepsin B (CathB) homologue in Arabidopsis and Nicotiana benthamiana demonstrated its potential role in promoting HR (Gilroy et al., 2007; McLellan et al., 2009). In Arabidopsis, cathepsin-like proteins also engage autophagic components that function in HR development (Hofius et al., 2009).

\section{NO PRODUCTION IN MAMMALIAN AND PLANT CELLS}

In mammalian cells, NO is synthesized as a by-product of the conversion of L-arginine to L-citruline under the catalysis of a family of enzymes called nitric oxide synthases (NOS) (Fig. 1A). Three NOS isoforms have been identified: one inducible (iNOS, type II), and two constitutive, the neuronal (nNOS, type I) and endothelial (eNOS, type III) enzymes (Marsden et al., 1993; Michel and Feron, 1997). Immune system-related NOS is an inducible and calcium-independent enzyme that produces NO in sufficient quantities to cause deleterious effects to several pathogenic agents (Simmons and Murphy, 1992; Magalhaes et al., 2006). In addition, new isoforms or mitochondrial variants of NOS (mtNOS) have since been described in rat liver (Ghafourifar and Richter, 1997; Giulivi et al., 1998), thymus (Bustamante et al., 2000), and brain (Riobo et al., 2002). mtNOS is bound to mitochondrial cytochrome $\mathrm{c}$ oxidase (COX) (Persichini et al., 2005) and to complex I (Franco et al., 2006), thus favoring a steric relationship between the released $\mathrm{NO}$ and the control of respiration. NO is critical for numerous biological processes, including PCD, and it functions through both cGMPdependent and-independent pathways. A key cGMPindependent mechanism is S-nitrosylation (or S-nitrosation), in which protein cysteine thiol reacts with $\mathrm{NO}$ in the presence of an electron acceptor to form an S-NO bond. This has emerged as a central, redox-based, post-translational modification (Whiteman et al., 2006).

In plants, three routes to yield NO have been described

A

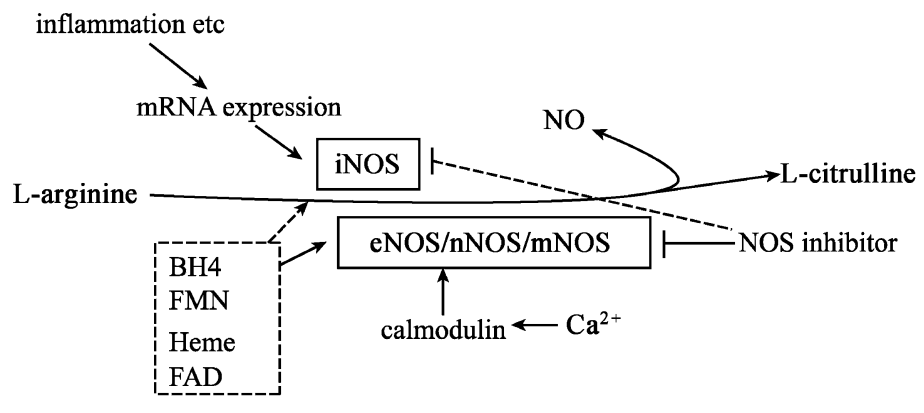

B

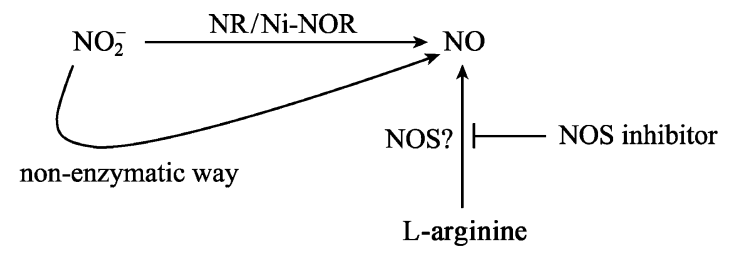

Figure 1. NO production in mammalian (A) and plant (B) cells. 
(Fig. 1B): non-enzymatic conversion of nitrite to $\mathrm{NO}$ in the apoplast, nitrate reductase (NR)-dependent NO formation, and NOS-like activity that is arginine-dependent (Leitner et al., 2009). Decreased NO synthesis and PCD in the presence of NOS inhibitor suggested the involvement of an NOS-like enzyme in plants, but this enzyme remains enigmatic (Pedroso et al., 2000). One potential candidate for a plant NOS, AtNOA1/RIF1, was subsequently demonstrated not to exhibit NOS activity. Rather, AtNOA1/RIF1 functions as a chloroplast-targeted GTPase, which may be essential for proper ribosome assembly (Moreau et al., 2008).

NO was initially found to play a crucial role in mediating plant defense reactions against bacterial pathogens (Delledonne et al., 1998). In Arabidopsis, it was proposed that NO could induce cell death independent of $\mathrm{H}_{2} \mathrm{O}_{2}$, which is also generated during the defense response, because agents that depleted $\mathrm{H}_{2} \mathrm{O}_{2}$ production did not affect NO-mediated cell death (Clarke et al., 2000). However, other data suggests that $\mathrm{NO}$ and $\mathrm{H}_{2} \mathrm{O}_{2}$ function in combination to elaborate $\mathrm{HR}$ cell death following pathogen recognition (Delledonne et al., 2001).

$\mathrm{NO}$ is now well known to influence numerous physiological processes throughout the entire plant life cycle. For example, $\mathrm{NO}$ is involved in germination, leaf expansion, lateral root development, flowering, stomatal closure, cell death and defense against biotic and abiotic stresses (Wilson et al., 2008; Leitner et al., 2009). Whereas descriptions of NOmediated processes are accumulating, the plant signaling pathways governed by $\mathrm{NO}$ are still largely unknown. In addition to $\mathrm{NO}$, a series of related molecules, collectively known as reactive nitrogen species (RNS) are also formed. RNS comprises not only the $\mathrm{NO}$ radical $\left(\mathrm{NO}^{-}\right)$and nitrosonium $\left(\mathrm{NO}^{+}\right)$ions, but also peroxynitrite $\left(\mathrm{ONOO}^{-}\right)$, S-nitrosothiols, higher oxides of nitrogen and dinitrosyl-iron complexes; in short, all NO derivatives can effect NO-dependent modifications (Di Stasi et al., 2002).

\section{CELL DEATH SIGNAL CASCADES REGULATED BY S-NITROSYLATION}

Emerging data in animals suggests that S-nitrosylation has a central role in the regulation of cell death. For example, glyceraldehyde 3-phosphate dehydrogenase (GAPDH) is Snitrosylated at its active site, Cys-145, which promotes its association with the E3-ligase, Siah1, resulting in nuclear translocation of the SNO-GAPDH-Siah1 complex (Mannick, 2007). Within the nucleus, SNO-GAPDH stabilizes Siah1 and facilitates the ubiquitination and degradation of nuclear proteins (Hara et al., 2005), while independently, SNOGAPDH is acetylated and consequently activates the acetyltransferase p300/cAMP-response element-binding protein (CREB) binding protein (CBP), leading to the acetylation/ activation of downstream targets, including the tumor suppressor p53 (Sen et al., 2008). Both of these mechanisms promote cell death (Foster et al., 2009). Recently, Sen et al. (2009) reported that a $52 \mathrm{kDa}$ cytosolic protein, GOSPEL, which binds GAPDH in competition with Siah, retains GAPDH in the cytosol and prevents its nuclear translocation. Snitrosylation of GOSPEL at Cys-47 enhances GAPDHGOSPEL binding and has neuroprotective action (Fig. 2)

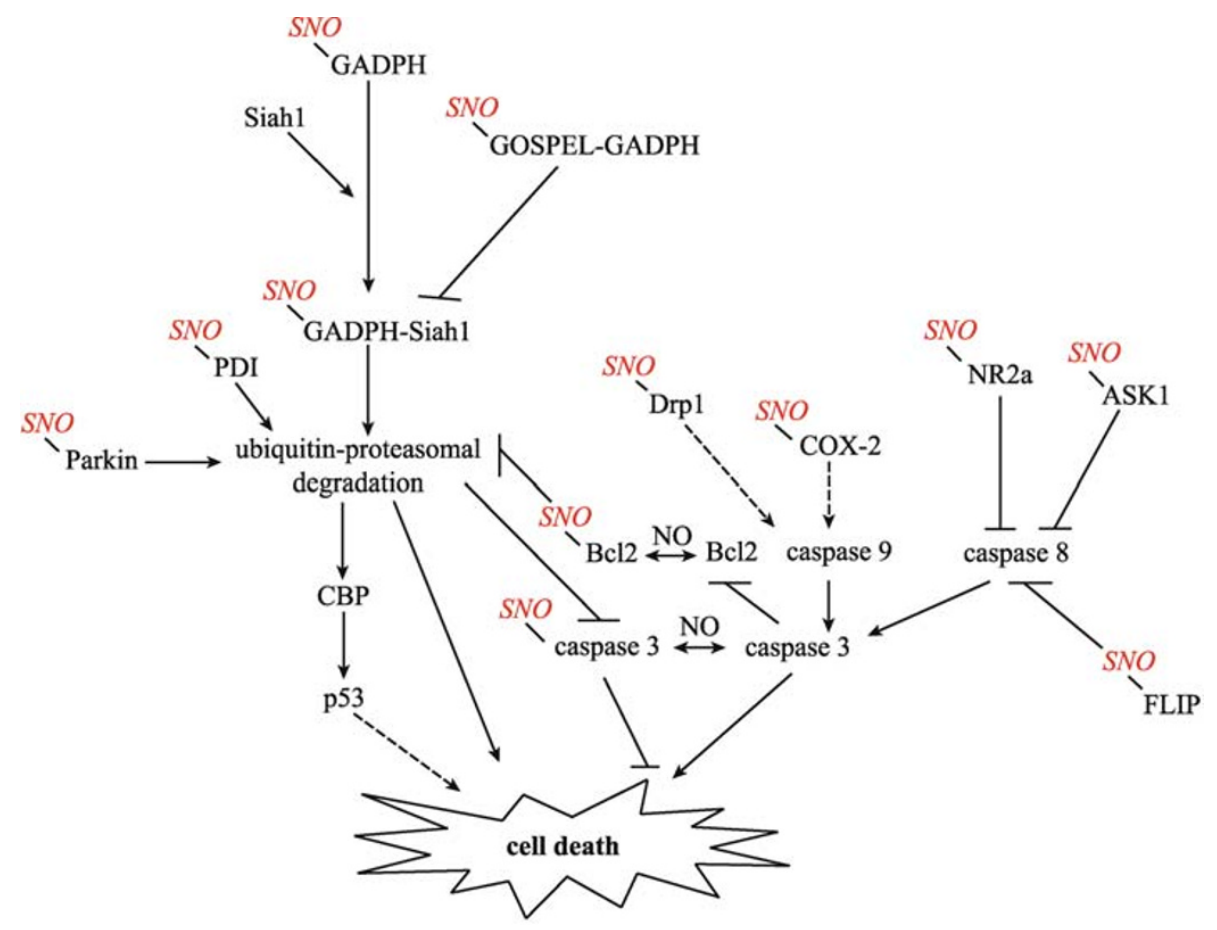

Figure 2. Cell death signal cascades regulated by S-nitrosylation in mammalian cells. 
(Sen et al., 2009). How NO selectively reacts with GADPH or GOSPEL in the same cytosolic situation still requires further study, although this may depend on the local concentration of NO.

Under normal physiological conditions, caspase 3 is constitutively S-nitrosylated to prevent it from initiating apoptosis (Tsang and Chung, 2009). When cells receive apotosic signals, however, caspase 3 is rapidly denitrosylated, and in this form it can cleave a number of key cellular proteins including poly (ADP-ribose) polymerase (PARP), an enzyme important for DNA repair. PARP is cleaved to an 89$\mathrm{kDa}$ fragment, which is often used as an indicator of apoptosis (Lopez and Ferrer, 2000). X-linked inhibitor of apoptosis (XIAP) binds to caspases and inhibits their activation during the execution phase of apoptosis. S-nitrosylation of XIAP does not affect its E3 ligase activity, but instead, it directly compromises its anticaspase- 3 and antiapoptotic function (Tsang et al., 2009).

In the mitochondrial induced cell death pathway (Fig. 2), Snitrosylation of COX-2, the terminal electron acceptor of the electron transport chain, reversibly inhibits mitochondrial respiration and contributes to enhanced oxidant production and PCD of lung cells (Carreras and Poderoso, 2007). The PDZ (postsynaptic density of the Drosophila septate junction protein discs-large, and the epithelial tight junction protein ZO-1) domain of nNOS, used as a dominant integrative peptide, blocks nNOS-COX-2 binding and abolishes Snitrosylation of COX-2 (Tian et al., 2008). NO triggers mitochondrial fragmentation by S-nitrosylating the mitochondrial division protein, dynamin-related protein1 (Drp1). SNODrp1 is increased in brains of human Alzheimer's disease patients and may thus contribute to the pathogenesis of neurodegeneration (Cho et al., 2009; Westermann, 2009). Dynamin also proved to be S-nitrosylated at $\mathrm{C} 607$ during endocytosis (Wang et al., 2006). On the other hand, NO also has anti-apoptotic function through S-nitrosylation of Bcl2, which inhibits ubiquitin-proteasomal degradation and thus inhibits apoptosis (Azad et al., 2006).

In the extrinsic pathway, binding of membrane ligands like TNF and Fas to membrane receptors triggers the activation of caspases and the induction of apoptosis (Peter and Krammer, 2003). FLICE (FADD-like ICE) inhibitory protein (FLIP) inhibits apoptotic signaling by interfering with the binding of caspase 8 to the adaptor protein at the Fas receptor complex. S-nitrosylation of Cys-254 and-259 on FLIP after Fas stimulation inhibits the ubiquitination and proteasomal degradation of FLIP (Chanvorachote et al., 2005). As a result, FLIP levels are increased and caspase 8 activation and apoptosis are inhibited (Mannick, 2007). Apoptosis signal-regulating kinase 1 (ASK1), another protein that stimulates apoptosis when activated, is also S-nitrosylated on Cys-869, which inhibits its activation by decreasing the binding of ASK1 to its substrate kinases MAPK kinase 3 (MKK3) or MKK6 (Park et al., 2004). Similarly, stimulation of the N-Methyl-D-
Aspartate (NMDA) class of glutamate receptors in neurons leads to increased NOS activation that down regulates NMDA receptor activity and apoptosis via S-nitrosylation of the NR2a regulatory subunit of the NMDA receptor (Choi and Lipton, 2000; Choi et al., 2000; Mannick, 2007). Taken together, Snitrosylation of different target proteins elaborates diverse and often opposing functions on cell death control. How these modifications are integrated to form a robust system for death control remains a distant goal.

\section{NO FUNCTIONS IN IMMUNITY AND NEURODEGENERATIVE DISEASE}

It is becoming evident that NOS activity is associated with human diseases and disorders. Immune cell death is very important for disease development. NO concentration in immune cells plays a significant role in determining thymocyte fate. Recently, it was shown that NO augments the accumulation of activated human $T$ cells principally by inhibiting cytokine deprivation-induced cell death through Snitrosylation of caspases (Choy and Pober, 2009). The regulation of rat sarcoma/extracellular signal-regulated kinase1 (Ras/ERK) signaling in antigen-stimulated T cells is compartmentalized by the local production of NO. eNOS positively regulates Ras activation during antigen-specific $T$ cell-APC interactions by S-nitrosylation on the Golgi, thus favoring activation-induced T cell death (Ibiza et al., 2008). In human lung carcinoma cells, Caveolin (Cav)-1, a 21-24 KDa structural protein component of plasma membrane microdomains, termed caveolae, has been shown to function in vesicular trafficking, signal transduction, and cancer progression (Galbiati et al., 2001). Cav-1 was rapidly S-nitrosylated by NO after cell detachment and inhibition of this Snitrosylation by DTT blocked the effect of NO on Cav-1 ubiquitination (Chanvorachote et al., 2009).

$\mathrm{S}$-nitrosylation is also a significant cause of NO-mediated neurotoxicity to neuronal cells, and neural dysfunction leads to neurodegenerative disorders. For instance, during cerebral ischemia, matrix metalloproteinase-9 (MMP-9) colocalizes with $\mathrm{nNOS}$ and is S-nitrosylated on a critical cysteine residue, which causes irreversible activation of MMP-9, and as a result, extracellular proteolytic cascades which disrupt the extracellular matrix and contribute to stroke formation are triggered (Gu et al., 2002). NO is thought to play a key role in the pathogenesis of Parkinson's disease (PD) through the impairment of prosurvival proteins, such as parkin, a protective ubiquitin protein ligase that is important for the survival of dopaminergic neurons. Parkin is S-nitrosylated both in vitro and in vivo in PD patients, indicating that abnormal S-nitrosylation plays an important role in the process of neurodegeneration (Tsang et al., 2009). Furthermore, peroxiredoxin 2 (Prx2) is S-nitrosylated at two critical cysteine residues (Cys-51 and Cys-172), preventing its reaction with peroxides. Increased SNO-Prx2 in human PD 
brains was observed, which inhibited both its enzymatic activity and protective function from oxidative stress (Fang et al., 2007). Recent evidence also suggests that NO contributes to degenerative conditions by S-nitrosylating protein disulphide isomerase (PDI), which is located in the ER lumen and prevents neurotoxicity associated with ER stress and protein misfolding (Nakamura and Lipton, 2008). In brains manifesting sporadic Parkinson's or Alzheimer's disease, Snitrosylation inhibits PDI's enzymatic activity, leading to the accumulation of polyubiquitinated proteins, which activates the unfolded protein response (Uehara et al., 2006). Activation of this stress pathway, may be linked to the development of sporadic neurodegenerative diseases (Uehara, 2007). Snitrosylation of parkin also eventually leads to the accumulation of unfolded proteins and subsequent neuronal cell death (Nakamura and Lipton, 2009).

\section{SIMILARITIES OF PLANT HR CELL DEATH TO MAMMALIAN PCD}

The HR is a form of PCD that is engaged during plant defense against microbial pathogens and is thought to restrict the extent of attempted infection (Mur et al., 2008). HR exhibits some features that are typical of animal cell death, such as chromatin condensation, a requirement for gene expression and activation of a caspase-like cascade (Mur et al., 2008). It was also found that NO inhibits ATP synthesis in plant mitochondria via inhibition of COX activity (Yamasaki et al., 2001) and altered mitochondrial activity stimulates PCD in plant cells. In Arabidopsis, NO can function via inhibition of respiration, de-polarisation of the mitochondrial membrane potential and the release of mitochondrial cytochrome c, triggering a signal cascade at the mitochondrial level that accounts for about $20 \%$ of total cell death (Zottini et al., 2002). Cyclosporin A, an inhibitor of mitochondrial permeability transition pore (PTP) formation, inhibited NO-induced PCD as well as mitochondrial membrane potential (Saviani et al., 2002). Thus, PTP formation is one of the molecular targets of $N O$ to activate the PCD process in plants. Increased alternative oxidase (AOX) activity has also been observed during pathogen challenge of both Arabidopsis and tobacco (Simons et al., 1999). Huang et al. found that exposure to NO induced the expression of AOX. Inhibition of the AOX pathway increased NO sensitivity and cell death, suggesting a 'shunting' of the respiratory pathway via AOX (Huang et al., 2002).

Protein S-nitrosylation is also a significant regulatory component in the plant defense response, which also plays important roles in HR development (Feechan et al., 2005; Romero-Puertas et al., 2007). Caspase like activity during HR induction has been detected in several plants such as tomato, Arabidopsis suspension cultures and tobacco (Clarke et al., 2000). Treatment with caspase inhibitors prevented the induction of $\mathrm{HR}$, while no structural homologs of caspases were found in plant genomes. However, several related proteins, named metacaspases, have been found and proposed to be the functional homologs of mammalian caspases in plant, which are regulators or executors of cell death (Mottram et al., 2003). Based on sequence and structure, nine Arabidopsis metacaspase (AtMC) genes have been described. AtMC4 and AtMC9 have been shown to be arginine/lysine-specific cysteine proteases that did not cleave caspase-specific target sites (Vercammen et al., 2004). In the absence of an upstream activator protease, AtMC9 is locked in its inactive proform through S-nitrosylation at Cys-147. Unexpectedly, S-nitrosylation does not affect AtMC9 activity in its processed mature form. A second catalytic cysteine residue (Cys-29 in AtMC9), which is highly conserved in all known metacaspases but is absent in all members of the caspase and paracaspase families, can function as an alternative nucleophile in AtMC9 when Cys147 is S-nitrosylated. Like mammalian caspases, plant metacaspases can be kept inactive through S-nitrosylation of a critical Cys residue but are insensitive to S-nitrosylation when matured (Delledonne, 2005). S-nitrosylation of Arabidopsis cytosolic GAPDH could also play a role in the regulation of cell death, as it causes GAPDH inactivation and potentially induces translocation to the nucleus (Holtgrefe et al., 2008).

\section{NO SIGNALING UNDERLYING PLANT HR INDUCTION}

$\mathrm{NO}$ and ROS synthesis are routine requirements for plant cells to undergo HR, however, evidence has been presented that either can induce HR independently of the other (Clarke et al., 2000). The emerging evidences also suggest significant cross-talk between NO and ROS (Delledonne et al., 2001), although the molecular details of this interchange remain undefined. Significantly, Delledonne et al. have shown that the NO:superoxide ratio might determine PCD. If superoxide levels are greater than those of NO, then NO reacts with superoxide to form peroxynitrite, which does not result in PCD. Surprisingly, plant cells appear to be relatively tolerant of this particularly reactive molecule. However, if more NO than superoxide occurs, then $\mathrm{NO}$ reacts cooperatively with $\mathrm{H}_{2} \mathrm{O}_{2}$ (arising from dismutation of superoxide) to induce cell death (Delledonne et al., 2001). In tobacco, neither NO nor $\mathrm{H}_{2} \mathrm{O}_{2}$ alone at low concentrations had any effect on PCD or on the activity of the redox responsive gene that encodes phenylalanine ammonia lyase (PAL). However, treatment with both $\mathrm{H}_{2} \mathrm{O}_{2}$ and $\mathrm{NO}$ together triggered a substantial increase in cell death, with characteristics of PCD, and PAL activity was also induced. In the study of $\mathrm{Cd}^{2+}$-induced cell death in Arabidopsis cell suspension cultures, NO production preceeds ROS accrual following $\mathrm{CdCl}_{2}$ treatment (De Michele et al., 2009). Arabidopsis PrxllE possesses peroxynitrite reductase activity and therefore might control the 
bioavailability of peroxynitrite (ONOO-) (Romero-Puertas et al., 2007). PrxllE is inhibited by S-nitrosylation, causing increased $\mathrm{ONOO}^{-}$accrual. The increase in this RNS then results in lipidoxidation and tyrosine nitration, which suggests that NO might regulate the effect of its own reactive species through S-nitrosylation of crucial components of the antioxidant defense system (Romero-Puertas et al., 2007). Taken together, these data imply that NO interacts with ROS pathway to affect the cellar redox status which may subsequently mediate the induction of $\mathrm{HR}$ cell death.

A number of plant hormones, including auxins, cytokinins, gibberellins, abscisic acid (ABA), jasmonates and ethylene have been implicated in plant cell death control (Tamaoki, 2008). NO routinely exhibits crosstalk with these hormone signaling pathways. For example, in barley aleurone layers, gibberellic acid (GA)-induced PCD was delayed in the presence of NO. This form of PCD is correlated with loss of activity of the antioxidants catalase and superoxide dismutase. However, NO did not inhibit GA-induced alpha-amylase expression and activity, suggesting that NO does not have a general effect on cellular metabolism, but rather acts as a specific endogenous modulator of PCD (Beligni et al., 2002). A novel role for cytokinins in the induction of PCD that required $\mathrm{NO}$ but not $\mathrm{H}_{2} \mathrm{O}_{2}$ has also been proposed (Lamotte et al., 2004). 6-benzyl aminopurine (6-BA) also induces NO production in plants at the level of root tissues, which can be reduced by pretreatment with a NO scavenger 2-(4carboxyphenyl)-4,4,5,5-tetramethy limidazoline-1-oxyl-3oxide (PTIO) and NOS inhibitors.

In ozone-induced HR-like cell death, NO accumulation preceded accumulation of ethylene, salicylic acid (SA) and leaf injury (Rao and Davis, 2001; Ogawa et al., 2005; Tamaoki, 2008). S-nitrosylation of methionine adenyl transferase1 (MAT1), which is involved in ethylene biosynthesis, inhibits ethylene production (Lindermayr et al., 2006). Thus, production of this key phytohormone and its associated effects is modulated by NO function. Our recently study on Arabidopsis SA binding protein 3 (SABP3) revealed that it is
S-nitrosylated at Cys-280. S-nitrosylation inhibited its carbonic anhydrase activity and SA-binding capacity, which could contribute to a negative feedback loop that modulates the plant defense response (Wang et al., 2009). Non-expression of pathogenesis-related protein 1 (NPR1), a crucial component of disease resistance and SA signal cross-talk, has also recently been found to be regulated by S-nitrosylation of Cys156 , which facilitates its oligomerization and maintains protein homeostasis upon SA induction (Tada et al., 2008). Furthermore, methyl jasmonate (Me-JA) pretreatment of the Cvi-0 accession of Arabidopsis decreased ozone-induced SA concentrations and completely abolished ozone-induced cell death. Thus, demonstrating an antagonistic relationship between JA- and SA-signaling pathways in controlling the magnitude of ozone-induced cell death (Tamaoki, 2008). Moreover, allene oxide cyclase (AOC), a JA biosynthetic enzyme, has been shown to be S-nitrosylated during the HR. Hence, NO might also control JA biosynthesis (RomeroPuertas et al., 2008). Collectively, these findings have provided significant insights into our current appreciation of the mechanisms underpinning NO function in plants, revealing that the NO pathway in plant PCD is highly complex and is mediated at least in part by crosstalk with several phytohormone signaling networks.

\section{CONCLUSIONS}

PCD, which serves to eliminate unwanted cells, is essential for the maintenance of tissue homeostasis. NO and its related molecules are important messengers that play central roles in this process. This redox molecule regulates PCD through Snitrosylation of a plethora of target proteins. NO can prevent or induce neuronal apoptosis depending on cellular redox state and its concentration. Different source of NOS may interact with target protein and cause locally high concentration of NO and S-nitrosylation, which can activate a complex network of responses leading to apoptosis via mitochondrial, cell death receptors and GAPDH-Siah1 cascades. The

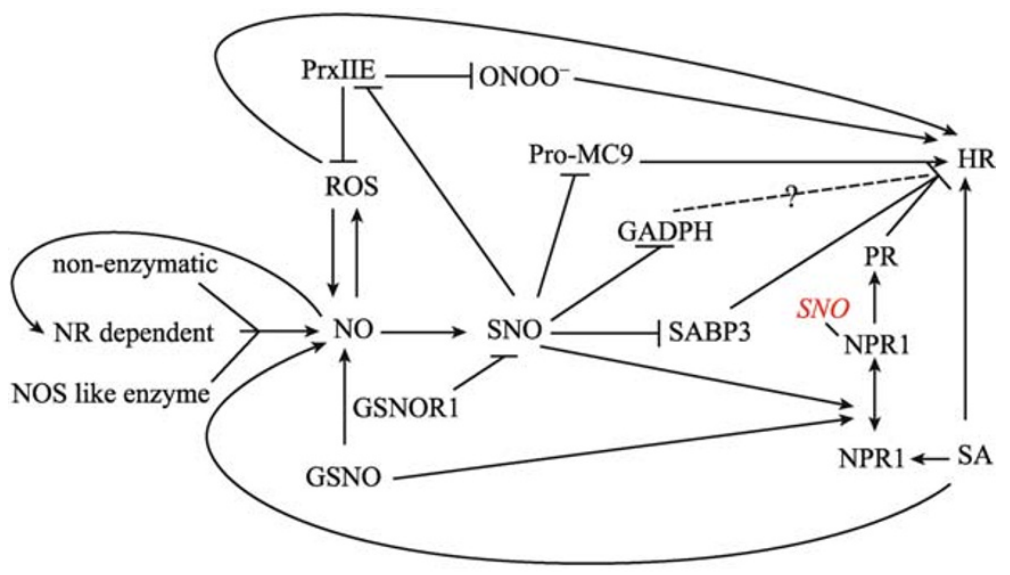

Figure 3. NO signaling regulated by S-nitrosylation in the process of HR. 
anti-apoptotic effect of $\mathrm{NO}$ can be mediated through a number of mechanisms, such as caspase inactivation, induction of cellular tumor antigen p53 gene expression, upregulation of cellular FLIP, and over-expression of Bcl-2 and Bcl-XL with subsequent inhibition of cytochrome $c$ release from the mitochondria (lyer et al., 2008). In contrast, hyper-Snitrosylation of parkin, PDI, Pdx2, XIAP and Drp1 are observed in brains from patients with neurological disorders and S-nitrosylation of these proteins is implicated in stressinduced neuronal cell death (Foster et al., 2009). Thus, there are significant therapeutic opportunities to develop pharmacological agents that modulate NO function, conveying protection against PCD-based neurodegenerative disorders.

In plants, apoptotic characteristics have been observed during development, HR and after abiotic stress, such as exposure to ozone, UV irradiation, chilling and salt stress (Dat et al., 2003). Cell death in plants has also been associated with caspase-like activities. S-nitrosylation of AtMC9, a potential executioner of PCD, is an intriguing example of how NO exerts its physiological functions through Snitrosylation (Belenghi et al., 2007; Holtgrefe et al., 2008). In addition to metacaspase 9, additional proteins (e.g., NPR1, SABP3, PrxllE, GADPH and MAT1) that might function in $P C D$, have been shown to be regulated by $S$-nitrosylation (Lindermayr et al., 2006; Romero-Puertas et al., 2007; Holtgrefe et al., 2008; Tada et al., 2008; Wang et al., 2009). These data demonstrate the important regulatory role of NO in plant PCD, which is just beginning to emerge. The current data implies that cell death control in plants may be underpinned by mechanisms distinct from those found in animals. Uncovering this molecular machinery may therefore reveal novel strategies for the regulation of $\mathrm{PCD}$.

\section{ACKNOWLEDGEMENTS}

This work was supported by funding from the National Natural Science Foundation of China (Grant Nos. 30600407, 30825029) and an international exchange grant provided by the National Natural Science Foundation of China and the Royal Society of Edinburgh.

\section{ABBREVIATIONS}

ABA, abscisic acid; AOC, allene oxide cyclase; AOX, alternative oxidase; ASK1, apoptosis signal-regulating kinase 1; 6-BA, 6-benzyl aminopurine; Bax bcl-2 associated $x$ protein; Bcl-2, B cell lymphoma/ lewkmia-2; Cav-1, Caveolin-1; CBP, CREB binding protein; cGMP, cyclic guanosine monophosphate; COX, cytochrome c oxidase; CREB, acetyltransferase p300/cAMP-response element-binding protein; Drp1,dynamin-related protein1; FLIP, FLICE inhibitory protein; $\mathrm{HR}$, hypersensitive response; MAPK, mitogen-activated protein kinase; MAT1, methionine adenosyltransferase 1; MC, metacaspase; MEKK, MAPK/ERK kinase kinase; MKK3, mitogen activated protein kinase kinase-3; MMP-9, matrix metalloproteinase-9; NO, nitric oxide; NOS, nitric oxide synthases; NPR1, non-expressor of pathogenesisrelated protein 1; NR, nitrate reductase; PAL, phenylalanine ammonia-lyase; PARP, poly(ADP-ribose) polymerase; PCD, programmed cell death; PD, Parkinson's disease; PDI, protein disulfide isomerase; PDZ, postsynaptic density of the Drosophila septate junction protein discs-large, and the epithelial tight junction protein ZO-1; PrxlIE, peroxiredoxin II E; PTIO, 2-(4carboxyphenyl)-4,4,5,5-tetramethylimidazoline-1-oxyl-3-oxide; PTP, permeability transition pore; Ras/ERK, reliability, availability and serviceability/extracellular signalregulated kinases; RNS, reactive nitrogen species; SA, salicylic acid; SABP3, SA binding protein 3; TNFR, tumor necrosis factor receptor; XIAP, X-linked inhibitors of apoptosis.

\section{REFERENCES}

Ameisen, J.C. (2002). On the origin, evolution, and nature of programmed cell death: a timeline of four billion years. Cell Death Differ 9, 367-393.

Azad, N., Vallyathan, V., Wang, L., Tantishaiyakul, V., Stehlik, C., Leonard, S.S., and Rojanasakul, Y. (2006). S-nitrosylation of Bcl-2 inhibits its ubiquitin-proteasomal degradation. A novel antiapoptotic mechanism that suppresses apoptosis. J Biol Chem 281, 34124-34134.

Belenghi, B., Romero-Puertas, M.C., Vercammen, D., Brackenier, A., Inze, D., Delledonne, M., and Van Breusegem, F. (2007). Metacaspase activity of Arabidopsis thaliana is regulated by Snitrosylation of a critical cysteine residue. J Biol Chem 282, 1352-1358.

Beligni, M.V., Fath, A., Bethke, P.C., Lamattina, L., and Jones, R.L. (2002). Nitric oxide acts as an antioxidant and delays programmed cell death in barley aleurone layers. Plant Physiol 129, 1642-1650.

Bustamante, J., Bersier, G., Romero, M., Badin, R.A., and Boveris, A. (2000). Nitric oxide production and mitochondrial dysfunction during rat thymocyte apoptosis. Arch Biochem Biophys 376, 239-247.

Carreras, M.C., and Poderoso, J.J. (2007). Mitochondrial nitric oxide in the signaling of cell integrated responses. Am J Physiol Cell Physiol 292, C1569-1580.

Chanvorachote, P., Nimmannit, U., Lu, Y., Talbott, S., Jiang, B.H., and Rojanasakul, Y. (2009). Nitric oxide regulates lung carcinoma cell anoikis through inhibition of ubiquitin-proteasomal degradation of caveolin-1. J Biol Chem. In Press.

Chanvorachote, P., Nimmannit, U., Wang, L., Stehlik, C., Lu, B., Azad, N., and Rojanasakul, Y. (2005). Nitric oxide negatively regulates Fas CD95-induced apoptosis through inhibition of ubiquitinproteasome-mediated degradation of FLICE inhibitory protein. $\mathrm{J}$ Biol Chem 280, 42044-42050.

Cho, D.H., Nakamura, T., Fang, J., Cieplak, P., Godzik, A., Gu, Z., and Lipton, S.A. (2009). S-nitrosylation of Drp1 mediates beta-amyloidrelated mitochondrial fission and neuronal injury. Science 324 , 102-105.

Choi, Y.B., and Lipton, S.A. (2000). Redox modulation of the NMDA receptor. Cell Mol Life Sci 57, 1535-1541.

Choi, Y.B., Tenneti, L., Le, D.A., Ortiz, J., Bai, G., Chen, H.S., and Lipton, S.A. (2000). Molecular basis of NMDA receptor-coupled ion channel modulation by S-nitrosylation. Nat Neurosci 3, 15-21.

Choy, J.C., and Pober, J.S. (2009). Generation of NO by bystander human CD8 T cells augments allogeneic responses by inhibiting cytokine deprivation-induced cell death. Am J Transplant. In press.

Clarke, A., Desikan, R., Hurst, R.D., Hancock, J.T., and Neill, S.J. (2000). NO way back: nitric oxide and programmed cell death in 
Arabidopsis thaliana suspension cultures. Plant J 24, 667-677.

Danial, N.N., and Korsmeyer, S.J. (2004). Cell death: critical control points. Cell 116, 205-219.

Dat, J.F., Pellinen, R., Beeckman, T., Van De Cotte, B., Langebartels, C., Kangasjarvi, J., Inze, D., and Van Breusegem, F. (2003). Changes in hydrogen peroxide homeostasis trigger an active cell death process in tobacco. Plant J 33, 621-632.

De Michele, R., Vurro, E., Rigo, C., Costa, A., Elviri, L., Di Valentin, M., Careri, M., Zottini, M., Sanita di Toppi, L., and Lo Schiavo, F. (2009). Nitric oxide is involved in cadmium-induced programmed cell death in Arabidopsis suspension cultures. Plant Physiol 150, 217-228.

Delledonne, M. (2005). NO news is good news for plants. Curr Opin Plant Biol 8, 390-396.

Delledonne, M., Xia, Y., Dixon, R.A., and Lamb, C. (1998). Nitric oxide functions as a signal in plant disease resistance. Nature 394, 585-588.

Delledonne, M., Zeier, J., Marocco, A., and Lamb, C. (2001). Signal interactions between nitric oxide and reactive oxygen intermediates in the plant hypersensitive disease resistance response. Proc Natl Acad Sci U S A 98, 13454-13459.

Di Stasi, A.M., Mallozzi, C., Macchia, G., Maura, G., Petrucci, T.C., and Minetti, M. (2002). Peroxynitrite affects exocytosis and SNARE complex formation and induces tyrosine nitration of synaptic proteins. J Neurochem 82, 420-429.

Dragovich, T., Rudin, C.M., and Thompson, C.B. (1998). Signal transduction pathways that regulate cell survival and cell death. Oncogene 17, 3207-3213.

Elbaz, M., Avni, A., and Weil, M. (2002). Constitutive caspase-like machinery executes programmed cell death in plant cells. Cell Death Differ 9, 726-733.

Fang, J., Nakamura, T., Cho, D.H., Gu, Z., and Lipton, S.A. (2007). Snitrosylation of peroxiredoxin 2 promotes oxidative stress-induced neuronal cell death in Parkinson's disease. Proc Natl Acad Sci U S A 104, 18742-18747.

Feechan, A., Kwon, E., Yun, B.W., Wang, Y., Pallas, J.A., and Loake, G.J. (2005). A central role for S-nitrosothiols in plant disease resistance. Proc Natl Acad Sci U S A 102, 8054-8059.

Foster, M.W., Hess, D.T., and Stamler, J.S. (2009). Protein Snitrosylation in health and disease: a current perspective. Trends Mol Med 15, 391-404.

Franco, M.C., Arciuch, V.G., Peralta, J.G., Galli, S., Levisman, D., Lopez, L.M., Romorini, L., Poderoso, J.J., and Carreras, M.C. (2006). Hypothyroid phenotype is contributed by mitochondrial complex I inactivation due to translocated neuronal nitric-oxide synthase. J Biol Chem 281, 4779-4786.

Galbiati, F., Volonte, D., Liu, J., Capozza, F., Frank, P.G., Zhu, L., Pestell, R.G., and Lisanti, M.P. (2001). Caveolin-1 expression negatively regulates cell cycle progression by inducing $G(0) / G(1)$ arrest via a p53/p21(WAF1/Cip1)-dependent mechanism. Mol Biol Cell 12, 2229-2244.

Ghafourifar, P., and Richter, C. (1997). Nitric oxide synthase activity in mitochondria. FEBS Lett 418, 291-296.

Gilroy, E.M., Hein, I., van der Hoorn, R., Boevink, P.C., Venter, E., McLellan, H., Kaffarnik, F., Hrubikova, K., Shaw, J., Holeva, M., et al. (2007). Involvement of cathepsin B in the plant disease resistance hypersensitive response. Plant J 52, 1-13.

Giulivi, C., Poderoso, J.J., and Boveris, A. (1998). Production of nitric oxide by mitochondria. J Biol Chem 273, 11038-11043.
Gu, Z., Kaul, M., Yan, B., Kridel, S.J., Cui, J., Strongin, A., Smith, J.W., Liddington, R.C., and Lipton, S.A. (2002). S-nitrosylation of matrix metalloproteinases: signaling pathway to neuronal cell death. Science 297, 1186-1190.

Hara, M.R., Agrawal, N., Kim, S.F., Cascio, M.B., Fujimuro, M., Ozeki, Y., Takahashi, M., Cheah, J.H., Tankou, S.K., Hester, L.D., et al. (2005). S-nitrosylated GAPDH initiates apoptotic cell death by nuclear translocation following Siah1 binding. Nat Cell Biol 7, 665-674.

Hengartner, M.O., and Bryant, J.A. (2000). Apoptotic cell death: from worms to wombats ... but what about the weeds? Symp Soc Exp Biol 52, 1-12.

Hofius, D., Schultz-Larsen, T., Joensen, J., Tsitsigiannis, D.I., Petersen, N.H., Mattsson, O., Jorgensen, L.B., Jones, J.D., Mundy, J., and Petersen, M. (2009). Autophagic components contribute to hypersensitive cell death in Arabidopsis. Cell 137, 773-783.

Holtgrefe, S., Gohlke, J., Starmann, J., Druce, S., Klocke, S., Altmann, B., Wojtera, J., Lindermayr, C., and Scheibe, R. (2008). Regulation of plant cytosolic glyceraldehyde 3-phosphate dehydrogenase isoforms by thiol modifications. Physiol Plant 133, 211-228.

Huang, X., von Rad, U., and Durner, J. (2002). Nitric oxide induces transcriptional activation of the nitric oxide-tolerant alternative oxidase in Arabidopsis suspension cells. Planta 215, 914-923.

Ibiza, S., Perez-Rodriguez, A., Ortega, A., Martinez-Ruiz, A., Barreiro, O., Garcia-Dominguez, C.A., Victor, V.M., Esplugues, J.V., Rojas, J.M., Sanchez-Madrid, F., et al. (2008). Endothelial nitric oxide synthase regulates N-Ras activation on the Golgi complex of antigen-stimulated T cells. Proc Natl Acad Sci U S A 105, 10507-10512.

lyer, A.K., Azad, N., Wang, L., and Rojanasakul, Y. (2008). Role of Snitrosylation in apoptosis resistance and carcinogenesis. Nitric Oxide 19, 146-151.

Jones, A.M. (2001). Programmed cell death in development and defense. Plant Physiol 125, 94-97.

Lamotte, O., Gould, K., Lecourieux, D., Sequeira-Legrand, A., Lebrun-Garcia, A., Durner, J., Pugin, A., and Wendehenne, D. (2004). Analysis of nitric oxide signaling functions in tobacco cells challenged by the elicitor cryptogein. Plant Physiol 135, 516-529.

Leitner, M., Vandelle, E., Gaupels, F., Bellin, D., and Delledonne, M. (2009). NO signals in the haze: nitric oxide signalling in plant defence. Curr Opin Plant Biol 12, 451-458.

Levine, A., Pennell, R.I., Alvarez, M.E., Palmer, R., and Lamb, C. (1996). Calcium-mediated apoptosis in a plant hypersensitive disease resistance response. Curr Biol 6, 427-437.

Lindermayr, C., Saalbach, G., Bahnweg, G., and Durner, J. (2006). Differential inhibition of Arabidopsis methionine adenosyltransferases by protein S-nitrosylation. J Biol Chem 281, 4285-4291.

Lopez, E., and Ferrer, I. (2000). Staurosporine- and H-7-induced cell death in SH-SY5Y neuroblastoma cells is associated with caspase- 2 and caspase- 3 activation, but not with activation of the FAS/FAS-L-caspase-8 signaling pathway. Brain Res Mol Brain Res 85, 61-67.

Magalhaes, C.R., Socodato, R.E., and Paes-de-Carvalho, R. (2006). Nitric oxide regulates the proliferation of chick embryo retina cells by a cyclic GMP-independent mechanism. Int J Dev Neurosci 24, 53-60.

Mannick, J.B. (2007). Regulation of apoptosis by protein S- 
nitrosylation. Amino Acids 32, 523-526.

Marsden, P.A., Heng, H.H., Scherer, S.W., Stewart, R.J., Hall, A.V., Shi, X.M., Tsui, L.C., and Schappert, K.T. (1993). Structure and chromosomal localization of the human constitutive endothelial nitric oxide synthase gene. J Biol Chem 268, 17478-17488.

McLellan, H., Gilroy, E.M., Yun, B.W., Birch, P.R., and Loake, G.J. (2009). Functional redundancy in the Arabidopsis Cathepsin B gene family contributes to basal defence, the hypersensitive response and senescence. New Phytol 183, 408-418.

Meier, P., Finch, A., and Evan, G. (2000). Apoptosis in development. Nature 407, 796-801.

Michel, T., and Feron, O. (1997). Nitric oxide synthases: which, where, how, and why? J Clin Invest 100, 2146-2152.

Moreau, M., Lee, G.I., Wang, Y., Crane, B.R., and Klessig, D.F. (2008). AtNOS/AtNOA1 is a functional Arabidopsis thaliana cGTPase and not a nitric-oxide synthase. J Biol Chem 283, 32957-32967.

Mottram, J.C., Helms, M.J., Coombs, G.H., and Sajid, M. (2003). Clan CD cysteine peptidases of parasitic protozoa. Trends Parasitol 19, 182-187.

Mur, L.A., Kenton, P., Lloyd, A.J., Ougham, H., and Prats, E. (2008). The hypersensitive response; the centenary is upon us but how much do we know? J Exp Bot 59, 501-520.

Nakamura, T., and Lipton, S.A. (2008). Emerging roles of Snitrosylation in protein misfolding and neurodegenerative diseases. Antioxid Redox Signal 10, 87-101.

Nakamura, T., and Lipton, S.A. (2009). Cell death: protein misfolding and neurodegenerative diseases. Apoptosis 14, 455 468.

Nicholson, D.W., and Thornberry, N.A. (1997). Caspases: killer proteases. Trends Biochem Sci 22, 299-306.

Nicholson, D.W., and Thornberry, N.A. (2003). Apoptosis. Life and death decisions. Science 299, 214-215.

Ogawa, D., Nakajima, N., Sano, T., Tamaoki, M., Aono, M., Kubo, A., Kanna, M., Ioki, M., Kamada, H., and Saji, H. (2005). Salicylic acid accumulation under $\mathrm{O} 3$ exposure is regulated by ethylene in tobacco plants. Plant Cell Physiol 46, 1062-1072.

Park, H.S., Yu, J.W., Cho, J.H., Kim, M.S., Huh, S.H., Ryoo, K., and Choi, E.J. (2004). Inhibition of apoptosis signal-regulating kinase 1 by nitric oxide through a thiol redox mechanism. J Biol Chem 279, 7584-7590.

Pedroso, M.C., Magalhaes, J.R., and Durzan, D. (2000). A nitric oxide burst precedes apoptosis in angiosperm and gymnosperm callus cells and foliar tissues. J Exp Bot 51, 1027-1036.

Persichini, T., Mazzone, V., Polticelli, F., Moreno, S., Venturini, G., Clementi, E., and Colasanti, M. (2005). Mitochondrial type I nitric oxide synthase physically interacts with cytochrome c oxidase. Neurosci Lett 384, 254-259.

Peter, M.E., and Krammer, P.H. (2003). The CD95(APO-1/Fas) DISC and beyond. Cell Death Differ 10, 26-35.

Rao, M.V., and Davis, K.R. (2001). The physiology of ozone induced cell death. Planta 213, 682-690.

Riobo, N.A., Melani, M., Sanjuan, N., Fiszman, M.L., Gravielle, M.C., Carreras, M.C., Cadenas, E., and Poderoso, J.J. (2002). The modulation of mitochondrial nitric-oxide synthase activity in rat brain development. J Biol Chem 277, 42447-42455.

Romero-Puertas, M.C., Campostrini, N., Matte, A., Righetti, P.G., Perazzolli, M., Zolla, L., Roepstorff, P., and Delledonne, M. (2008). Proteomic analysis of S-nitrosylated proteins in Arabidopsis thaliana undergoing hypersensitive response. Proteomics 8 , 1459-1469.

Romero-Puertas, M.C., Laxa, M., Matte, A., Zaninotto, F., Finkemeier, I., Jones, A.M., Perazzolli, M., Vandelle, E., Dietz, K.J., and Delledonne, M. (2007). S-nitrosylation of peroxiredoxin II $E$ promotes peroxynitrite-mediated tyrosine nitration. Plant Cell 19, 4120-4130.

Saviani, E.E., Orsi, C.H., Oliveira, J.F., Pinto-Maglio, C.A., and Salgado, I. (2002). Participation of the mitochondrial permeability transition pore in nitric oxide-induced plant cell death. FEBS Lett 510, 136-140.

Sen, N., Hara, M.R., Ahmad, A.S., Cascio, M.B., Kamiya, A., Ehmsen, J.T., Aggrawal, N., Hester, L., Dore, S., Snyder, S.H., et al. (2009). GOSPEL: a neuroprotective protein that binds to GAPDH upon S-nitrosylation. Neuron 63, 81-91.

Sen, N., Hara, M.R., Kornberg, M.D., Cascio, M.B., Bae, B.I., Shahani, N., Thomas, B., Dawson, T.M., Dawson, V.L., Snyder, S.H., et al. (2008). Nitric oxide-induced nuclear GAPDH activates p300/CBP and mediates apoptosis. Nat Cell Biol 10, 866-873.

Shi, Y. (2002). Mechanisms of caspase activation and inhibition during apoptosis. Mol Cell 9, 459-470.

Simmons, M.L., and Murphy, S. (1992). Induction of nitric oxide synthase in glial cells. J Neurochem 59, 897-905.

Simons, B.H., Millenaar, F.F., Mulder, L., Van Loon, L.C., and Lambers, H. (1999). Enhanced expression and activation of the alternative oxidase during infection of Arabidopsis with Pseudomonas syringae pv tomato. Plant Physiol 120, 529-538.

Tada, Y., Spoel, S.H., Pajerowska-Mukhtar, K., Mou, Z., Song, J., Wang, C., Zuo, J., and Dong, X. (2008). Plant immunity requires conformational changes [corrected] of NPR1 via S-nitrosylation and thioredoxins. Science 321, 952-956.

Tamaoki, M. (2008). The role of phytohormone signaling in ozoneinduced cell death in plants. Plant Signal Behav 3, 166-174.

Thornberry, N.A., and Lazebnik, Y. (1998). Caspases: enemies within. Science 281, 1312-1316.

Tian, J., Kim, S.F., Hester, L., and Snyder, S.H. (2008). Snitrosylation/activation of COX-2 mediates NMDA neurotoxicity. Proc Natl Acad Sci U S A 105, 10537-10540.

Tsang, A.H., and Chung, K.K. (2009). Oxidative and nitrosative stress in Parkinson's disease. Biochim Biophys Acta 1792, 643-650.

Tsang, A.H., Lee, Y.I., Ko, H.S., Savitt, J.M., Pletnikova, O., Troncoso, J.C., Dawson, V.L., Dawson, T.M., and Chung, K.K. (2009). S-nitrosylation of XIAP compromises neuronal survival in Parkinson's disease. Proc Natl Acad Sci U S A 106, 4900-4905.

Uehara, T. (2007). Accumulation of misfolded protein through nitrosative stress linked to neurodegenerative disorders. Antioxid Redox Signal 9, 597-601.

Uehara, T., Nakamura, T., Yao, D., Shi, Z.Q., Gu, Z., Ma, Y., Masliah, E., Nomura, Y., and Lipton, S.A. (2006). S-nitrosylated proteindisulphide isomerase links protein misfolding to neurodegeneration. Nature 441, 513-517.

Vaux, D.L., and Korsmeyer, S.J. (1999). Cell death in development. Cell 96, 245-254.

Vercammen, D., van de Cotte, B., De Jaeger, G., Eeckhout, D., Casteels, P., Vandepoele, K., Vandenberghe, I., Van Beeumen, J., Inze, D., and Van Breusegem, F. (2004). Type II metacaspases Atmc4 and Atmc9 of Arabidopsis thaliana cleave substrates after arginine and lysine. J Biol Chem 279, 45329-45336. 
Wang, G., Moniri, N.H., Ozawa, K., Stamler, J.S., and Daaka, Y. (2006). Nitric oxide regulates endocytosis by S-nitrosylation of dynamin. Proc Natl Acad Sci U S A 103, 1295-1300.

Wang, H., Li, J., Bostock, R.M., and Gilchrist, D.G. (1996). Apoptosis: A functional paradigm for programmed plant cell death induced by a host-selective phytotoxin and invoked during development. Plant Cell 8, 375-391.

Wang, Y.Q., Feechan, A., Yun, B.W., Shafiei, R., Hofmann, A., Taylor, P., Xue, P., Yang, F.Q., Xie, Z.S., Pallas, J.A., et al. (2009). Snitrosylation of AtSABP3 antagonizes the expression of plant immunity. J Biol Chem 284, 2131-2137.

Westermann, B. (2009). Nitric oxide links mitochondrial fission to Alzheimer's disease. Sci Signal 2, pe29.

Whiteman, M., Chua, Y.L., Zhang, D., Duan, W., Liou, Y.C., and
Armstrong, J.S. (2006). Nitric oxide protects against mitochondrial permeabilization induced by glutathione depletion: role of Snitrosylation? Biochem Biophys Res Commun 339, 255-262.

Wilson, I.D., Neill, S.J., and Hancock, J.T. (2008). Nitric oxide synthesis and signalling in plants. Plant Cell Environ 31, 622-631.

Yamasaki, H., Shimoji, H., Ohshiro, Y., and Sakihama, Y. (2001). Inhibitory effects of nitric oxide on oxidative phosphorylation in plant mitochondria. Nitric Oxide 5, 261-270.

Zhou, P., Qian, L., and ladecola, C. (2005). Nitric oxide inhibits caspase activation and apoptotic morphology but does not rescue neuronal death. J Cereb Blood Flow Metab 25, 348-357.

Zottini, M., Formentin, E., Scattolin, M., Carimi, F., Lo Schiavo, F., and Terzi, M. (2002). Nitric oxide affects plant mitochondrial functionality in vivo. FEBS Lett $515,75-78$. 